\title{
Idiopathic Hyperammonemia after Orthotopic Lung Transplantation
}

\author{
Angeline Nguyen and Tyson Kathleen* \\ Department of Anesthesiology, Temple University, USA
}

Submission: November 28, 2016; Published: January 05, 2017

*Corresponding author: Tyson Kathleen, Department of Anesthesiology, Lewis Katz School of Medicine, Temple University, Philadelphia, USA, Tel: (215)-707-3506; Email: Kathleen.tyson@tuhs.temple.edu

Keywords: Hyperammonemia; Lung transplant; Urea cycle

\section{Introduction}

Idiopathic hyperammonemia is characterized by increased serum ammonia levels ( $>200 \mathrm{umol} / \mathrm{L})$ and is sometimes associated with normal to slightly elevated liver function tests [1]. These patients often present with encephalopathy, cerebral edema, seizures, and coma. Idiopathic hyperammonemia has been reported after high dose chemotherapy, and organ transplants including Orthotopic lung transplant [2]. Hyperammonemia is a rare, severe, and often fatal complication. There are few cases reported in the literature since 1997, including one retrospective analysis of 807 lung transplants; only 8 patients were diagnosed with hyperammonemia [3]. The exact mechanism of idiopathic hyperammonemiais not fully understood with congenital or acquired defects in ammonia metabolism, as well as bacterial infection having been described [3].

Ammonia is primarily cleared by the liver's urea cycle. The urea cycle converts ammonia to urea through a series of intermediate reactions. Hyperammonemia can be the result of any number of inborn errors (congenital or acquired) of urea cycle metabolism. Another hepatic mechanism for ammonia clearance is through glutamate synthetase, which converts glutamate and ammonia to glutamine. In the kidneys, glutamine is broken down back into glutamate and ammonia, which is then excreted. If hepatic or renal elimination of ammonia is interrupted, then hyperammonemia can occur leading to severe consequences. We present a case below of a female patient who developed hyperammonemia after Orthotopic lung transplant.

\section{Case Presentation}

66 year old Caucasian female with past medical history significant for COPD (on 3 litres/minute home $\mathrm{O}_{2}$ at rest and 4litres/minute $\mathrm{O}_{2}$ with activity), emphysema, extensive smoking history, morbid obesity with body mass index 34 , obstructive sleep apnea using continuous positive airway pressure therapy, hypertension, hyperlipidaemia, and osteoporosis, presented to the hospital for single left lung transplant via anterolateral thoracotomy. The patient tolerated the procedure well and was transferred to the intensive care unit without any issues. Her post-operative course was initially complicated by acute hypoxic ventilator dependent respiratory failure.

She developed increasing supplemental oxygen requirements and had several bronchoscopies with endotracheal tube changes to help clear thick secretions. Vancomycin and meropenem were prescribed to treat pneumonia. On postoperative day 3 , the patient developed atrial fibrillation with a rapid ventricular response, which was treated with cardio version and digoxin. By postoperative day 4 , the patient's mental status became altered and continued to decline. A CT of the head showed no acute intracranial abnormalities. At this time, her blood ammonia levels were noted to be elevated at more than 30 milligrams per deciliter $(\mathrm{mg} / \mathrm{dL})$ and lactulose was started. Her ammonia levels continued to rise and rifaximin was added to her treatment. The patient subsequently became hemodynamically unstable and was unable to be weaned off the ventilator. She required vasopressor support and was placed on veno-venous ECMO.

Ammonia levels on postoperative day 8, now approximately $60 \mathrm{mg} / \mathrm{dL}$, had not responded to lactulose or rifaximin and she was placed on continuous veno-venous hemodialysis (CVVHD) and prescribed arginine $\mathrm{HCl}$. The patient had been on total parenteral nutrition and this was discontinued. An electroencephalogram was done to rule out seizures. The patient transiently responded to 
therapy, regaining consciousness and responding to commands. On postoperative day 12 , she became agitated and required sedation as she was still ventilated. Ammonia levels had risen to $234 \mathrm{mg} /$ $\mathrm{dL}$, and sodium benzoate and sodium phenyl acetate infusions initiated. The patient's ammonia levels began to gradually decline, but her respiratory status also declined. Anti-HLA antibodies were found and she was placed on plasmapheresis, high-dose steroids and IVIG. Ultimately, hemolysis due to plasmapheresis added to her complications. Despite efforts to correct her DIC, the patient was rapidly deteriorating and the family decided to withdraw care after multiple family meetings. The patient's ammonia level at time of death was $99 \mathrm{mg} / \mathrm{dL}$. The family declined an autopsy.

\section{Discussion}

The exact mechanism of idiopathic hyperammonemia is unknown, but logically, increased blood ammonia levels would be due to increased production or decreased metabolism of ammonia. Both types of mechanisms have been reported in the literature. Tuchman, et al. [4] looked at peri- and postmortem liver samples from two patients with hyperammonemia after lung transplant. They found decreased levels of glutamine synthase $(12 \%$ and $28 \%$ of normal) [4]. Bezinover, et al. [5] discovered an apparently acquired defect in the urea cycle in a renal transplant patient who developed postoperative hyperammonemia. The patient had increase orotic acid levels in his urine [5]. Bacterial infections have been identified as causing increased blood ammonia levels in patients. Specifically, Mycoplasma hominis splits arginine as an energy source, releasing large amounts of ammonia as a waste product. This bacterium has been identified as an infectious agent in a lung transplant patient who developed hyperammonemia [6].

Urea plasma infection has also been identified as the cause of hyperammonemia [7]. Once a post-transplant patient develops symptoms of lethargy and altered mental status, acute pathology should be ruled out with CT head and EEG, and ammonia levels checked early. If a patient is found to have symptomatic hyperammonemia, the excess ammonia needs to be removed as quickly and safely as possible. Most reported cases have been treated with multipronged approach. Ammonia has been shown to be effectively cleared with renal replacement therapy. One case series reported by the department of medicine at Washington University shows that prompt initiation of high flux intermittent hemodialysis in conjunction with other methods of lowering ammonia, can lead to better outcomes [3]. Increasing dialysis flux can also maximize small molecule solute clearance (ammonia is a low-molecular weight molecule).

The rapid removal of ammonia by hemodialysis does not cause disequilibrium syndrome since ammonia a gas and is not osmotically active. However, with high efficiency dialysis in these cases, nephrology should be on board to maintain electrolyte abnormalities. In addition to renal replacement therapy, ammonia can also be decreased by limiting nitrogen intake, bowel decontamination and by supplementing the endogenous nitrogen removing mechanisms. Endogenous ammonia production from protein catabolism can be limited by discontinuing TPN and enteral nutrition. Bowel decontamination with lactulose and rifaximin can also reduce the intestinal ammonia production. Arginine supplementation via intravenous infusion can help expedite ammonia uptake into the urea cycle, and therefore expedite ammonia excretion from the body (arginine is the immediate precursor to ornithine, an essential amino acids in the urea cycle) (Figure 1).

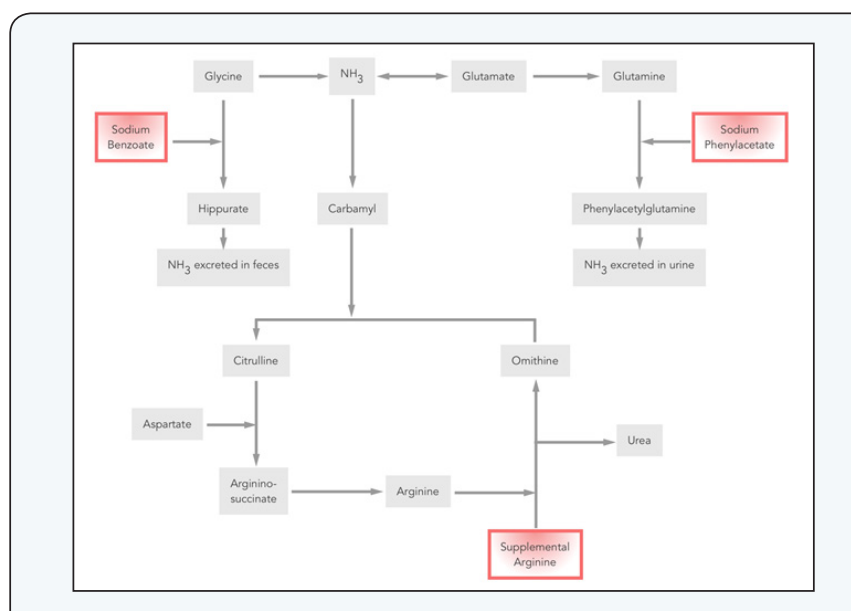

Figure 1: Alternative pathways of nitrogen waste removal in the urea cycle. Compounds in red boxes are administered to promote excretion of nitrogen waste.

Sodium Benzoate binds to glycine, leading to the formation of hippurate, which diverts ammonia away from the defective urea cycle and results in fecal excretion. Sodium phenyl acetate binds serum glutamine to form phenyl acetyl glutamine which is then excreted in the urine [8]. Despite the fact that we began CVVHD on our patient when her ammonia was $61 \mathrm{mg} / \mathrm{dL}$ and aggressively treated her with bowel decontamination, stopping exogenous proteins, starting an arginine hydrochloride infusion and ammunol (sodium benzoate and sodium phenyl acetate) infusion - her ammonia levels continued to rise, peaking at 234 $\mathrm{mg} / \mathrm{dL}$. Although her ammonia levels were trending down, her course was further complicated by acute rejection of her left lung transplant and disseminated intravascular coagulation.

\section{Conclusion}

Idiopathic hyperammonemia after Orthotopic lung transplant is a rare, but often fatal complication of unknown etiology. Currently, treatment of hyperammonemia is largely supportive with methods derived from case reports. More case reports and retrospective/prospective studies need to be conducted so that a standardized hyperammonemia protocol can be formulated.

\section{References}

1. Shawcross D, Jalan R (2005) The pathophysiologic basis of hepatic encephalopathy: central role for ammonia and inflammation. Cell Mol Life Sci 62(20): 2295-304.

2. Lichtenstein GR, Yang YX, Nunes FA, Lewis JD, Tuchman M, et al. (2000) Fatal hyperammonemia after Orthotopic lung transplantation. Ann Intern Med 132(4): 283-287. 
3. Chen C, Bain KB, Iuppa JA, Yusen RD, Byers DE, et al. (2016) Hyperammonemia Syndrome After Lung Transplantation: A Single Center Experience. Transplantation 100(3): 678-684.

4. Tuchman M, Lichtenstein GR, Rajagopal BS, McCann MT, Furth $\mathrm{EE}$, et al. (1997) Hepatic glutamine synthetase deficiency in fatal hyperammonemia after lung transplantation. Ann Intern Med 127(6) 446-449.

5. Bezinover D, Douthitt L, McQuillan PM, Khan A, Dalal P, et al. (2010) Fatal hyperammonemia after renal transplant due to late-onset urea cycle deficiency: a case report. Transplant Proc 42(5): 1982-1985.
6. Wylam ME, Kennedy CC, Hernandez NM, Peters SG, Maleszewski JJ, et al. (2013) Fatal hyperammonaemia caused by Mycoplasma hominis. Lancet 382(9908): 1956.

7. Bharat A, Cunningham SA, Scott Budinger GR, Kreisel D, DeWet CJ, et al. (2015) Disseminated Ureaplasma infection as a cause of fatal hyperammonemia in humans. Sci Transl Med 7(284): 284.

8. Berry GT, Bridges ND, Nathanson KL, Kaplan P, Clancy RR, et al. (1999) Successful use of alternate waste nitrogen agents and hemodialysis in a patient with hyperammonemic coma after heart-lung transplantation. Arch Neurol 56(4): 481-484.

Your next submission with JuniperPublishers will reach you the below assets

- Quality Editorial service

- Swift Peer Review

- Reprints availability

- E-prints Service

- Manuscript Podcast for convenient understanding

- Global attainment for your research

- Manuscript accessibility in different formats ( Pdf, E-pub, Full Text, Audio)

- Unceasing customer service

Track the below URL for one-step submission https://juniperpublishers.com/online-submission.php 